\title{
Importance of Solar Power Satellite
}

\author{
Reshmi Banerjee \\ Ph.D Student, Calcutta University, Kolkata, W.B., India
}

\begin{abstract}
The world need to find new sources of clean energy. Space solar power gathers energy from sunlight in space and transmits it wirelessly to earth. Space solar power can solve our energy and greenhouse gas emissions problems. The new millennium has introduced increased pressure for finding new renewable energy sources. The exponential increase in population has led to the global crisis such as global warming, environmental pollution and change and rapid decrease of fossil reservoirs. Space based solar power is the concept of collecting solar power in space for use in earth. It has been in research since the early 1970s.
\end{abstract}

Keywords: Microwave transmitter, Space debris, Solar concentrator, Solar energy, Solar power satellite.

\section{INTRODUCTION}

Space based solar power would differ from current solar collection methods in that means used to collect energy would reside on an orbiting satellite instead of an Earth's surface. Some projected benefits of such a system are a higher collection rate and a longer collection period due to the lack of a diffusing atmosphere and night time in space. Part of the solar energy (55-60\%) is lost on its way through the atmosphere by the effects of reflection and absorption. Space based solar power systems convert sunlight to microwaves outside the atmosphere, avoiding these losses, and the downtime due to the Earth's rotation. Radiation and micrometeoroid damage could become concerns for space based solar power.

The cost of launching a satellite into space is large. Maintenance of an earth based solar panel is relatively simple, but construction and maintenance on a solar panel in space would typically be done telerobotically. In addition to cost, astronauts working in GEO orbit are exposed to unacceptably high radiation dangers and risk and cost about one thousand times more than the same task done telerobotically. The space environment is hostile; panels suffer about 8 times the degradation they would on Earth.

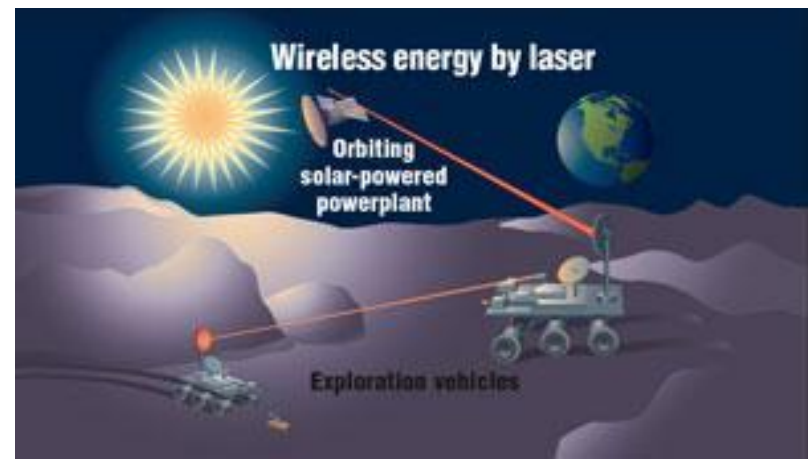

Fig. 1: Wireless energy by laser

Space debris is a major hazard to large objects in space, and all large structures such as solar power satellites have been mentioned as potential sources of orbital debris. The broadcast frequency of the microwave downlink (if used) would require isolating the solar power satellites away from other satellites.

\section{METHODOLOGY}

- Solar power satellite designs generally include the use of some manner of wireless power transmission.

- The collecting satellite would convert solar energy into electrical energy on board, powering a microwave transmitter or laser emitter, and focus its beam toward a collector on Earth's surface.

- A means of collecting solar power in space, for example, via solar concentrators, solar cells or a heat engine.

- A means of transmitting power to earth, for example via microwave or laser.

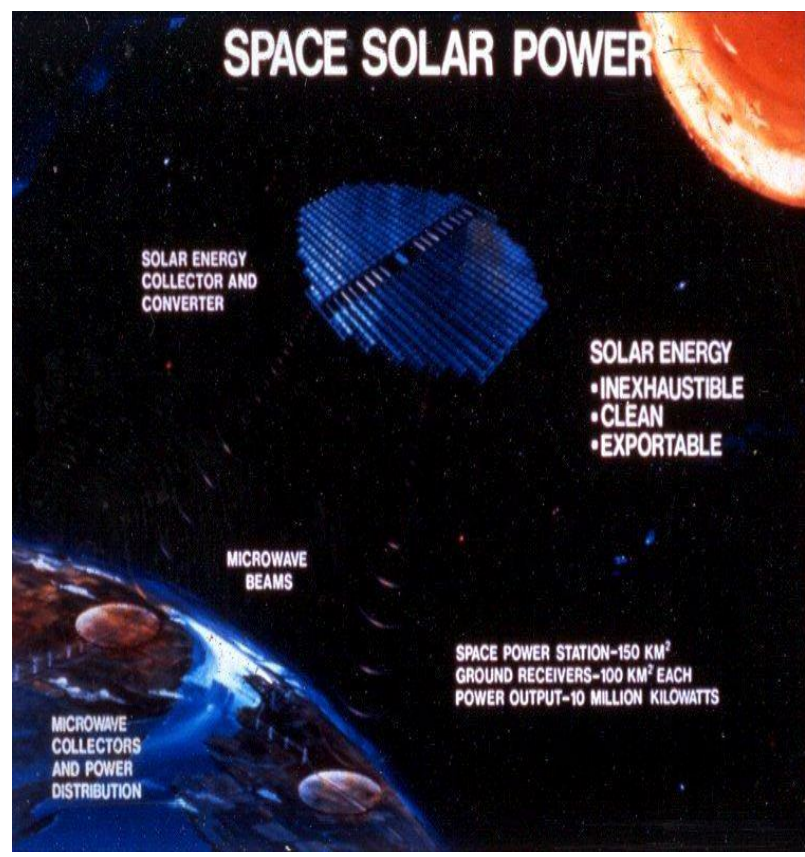

Fig. 2: Space solar power

- The space based portion will not need to support itself against gravity. It needs no protection from terrestrial wind or weather, but will have to cope with space hazards such as micrometers and solar flares.

A means of receiving power on earth, for example via a microwave antenna. 
INTERNATIONAL JOURNAL OF INNOVATIVE RESEARCH IN ELECTRICAL, ELECTRONICS, INSTRUMENTATION AND CONTROL ENGINEERING Vol. 4, Issue 2, February 2016

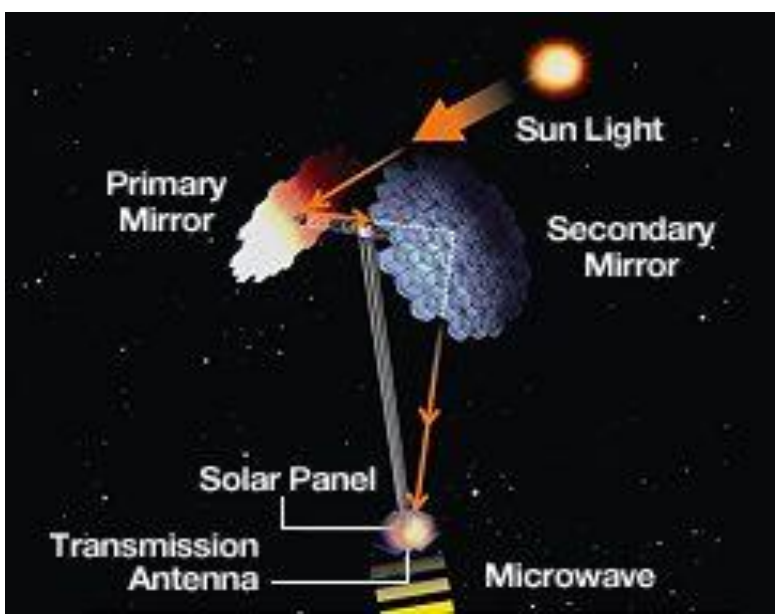

Fig. 3: Solar panel \& transmission antenna

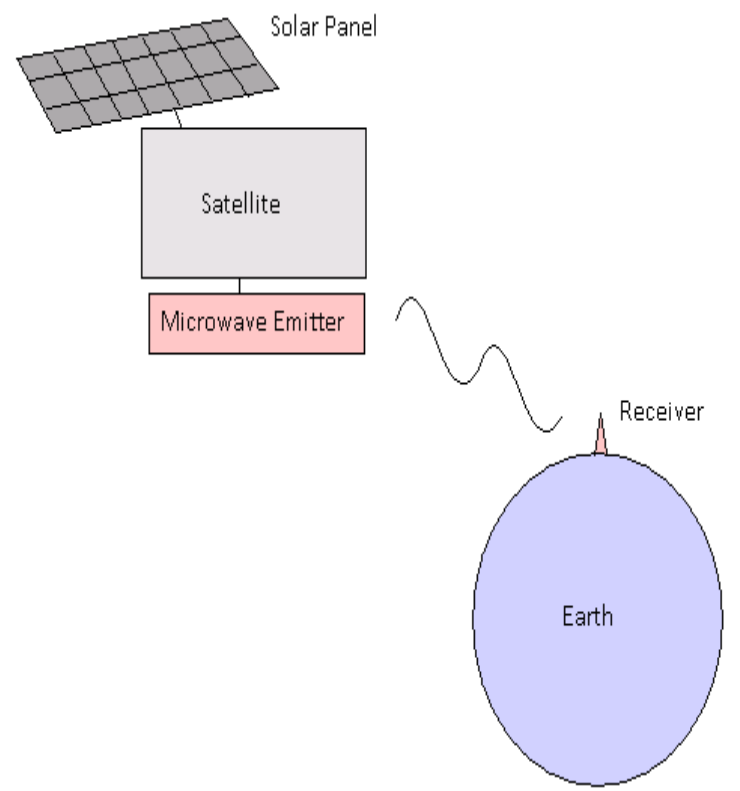

Fig. 4: Satellite, microwave emitter \& receiver

\section{RESULTS}

Collecting surfaces could receive much more intense sunlight, owing to the lack of obstructions such as atmospheric gasses, clouds, dust and other weather events. Consequently, the intensity in orbit is approximately $144 \%$ of the maximum attainable intensity on Earth's surface.

A satellite could be illuminated over $99 \%$ of the time, and be in Earth's shadow a maximum of only 72 minutes per night at the spring and fall equinoxes at local midnight. Orbiting satellites can be exposed to a consistently high degree of solar radiation, generally for 24 hours per day, whereas the average earth surface solar panels currently collect power for an average of $29 \%$ per day.

Power could be relatively quickly redirected directly to areas that need it most. A collecting satellite could possibly direct power on demand to different surface locations based on geographical base load or peak load power needs. Typical contracts would be for base load, continuous power, since peaking power is ephemeral.

\section{CONCLUSION}

One problem for the solar power satellite concept is the cost of space launches and the amount of material that would need to be launched. Reusable launch systems are predicted to provide lower launch costs to low Earth orbit.

\section{REFERENCES}

[1] G. D. Rai, Non Conventional Energy Sources, Khanna Publishers.

[2] Bansal Keemann, Meliss, Renewable Energy Sources and Conversion Technology, Tata Mc Graw Hill.

[3] Ashok V. Desai, Non Conventional Energy, New Age International Publishers Ltd.

[4] D. P. Kothari, Renewable Energy Resources and Emerging Technologies, Prentice Hall of India Pvt. Ltd.

[5] D. S. Chauhan, S. K. Srivastava, Non Conventional Energy Resources, New Age International Publishers.

[6] R. K. Rajput, Non Conventional Energy Sources and Utilisation, S. Chand.

[7] S. Hasan Saeed, D. K. Sharma, Non Conventional Energy Resources, Katson Books.

[8] S. A. Abbasi, Naseema Abbasi, Renewable Energy Sources and Their Environmental Impact, PHI.

[9] S P Sukhatme, Solar Energy, Tata McGraw Hill Company Limited.

\section{BIOGRAPHY}

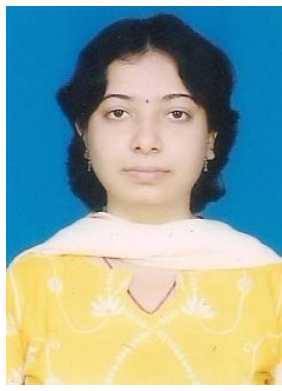

Reshmi Banerjee, have passed Madhyamik Examination from Christ Church Girls' High School, Higher Secondary from Dum Dum Motijheel Girls' Higher Secondary School in 2000, Diploma in Electrical Engineering from Jnan Chandra Ghosh Polytechnic in 2003, B. Tech from Meghnad Saha Institute of Technology in 2006 and M. Tech from Calcutta University in 2009. Now pursuing Ph.D. from Calcutta University in Energy Management. Have teaching experience of 9 years and industrial experience of 1 year. 